American Journal of Agricultural and Biological Sciences 4 (4): 289-297, 2009

ISSN 1557-4989

(C) 2009 Science Publications

\title{
Evaluation of Metarhizium anisopliae var. anisopliae (Deuteromycotina: Hyphomycete) Isolates and their Effects on Subterranean Termite Coptotermes curvignathus (Isoptera: Rhinotermitidae)
}

\author{
${ }^{1}$ Pik-Kheng Hoe, ${ }^{1}$ Choon-Fah J. Bong, ${ }^{2}$ Kadir Jugah and ${ }^{1}$ Amartalingam Rajan \\ ${ }^{1}$ Department of Crop Science, Faculty of Agriculture and Food Sciences, \\ University Putra Malaysia Bintulu Sarawak Campus, Jalan Nyabau, 97008 Bintulu, Sarawak, Malaysia \\ ${ }^{2}$ Department of Plant Protection, Faculty of Agriculture, \\ University Putra Malaysia, 43400 UPM Serdang, Selangor, Malaysia
}

\begin{abstract}
Problem statement: Coptotermes curvignathus (Isoptera: Rhinotermitidae) is a common termite pest found in oil palm plantation planted on peat. Currently, the control methods focus on using insecticides that lead to high cost and adverse effect to the environment. Approach: Biological control like the use of entomopathogens provides an alternative control method for termite infestation problem. However, several factors need to be investigated in order to obtain a virulent strain with potential to be developed into a biopesticide. Results: Three local isolates (MG, LR2 and TA) of Metarhizium anisopliae were obtained and identified as M. anisopliae var. anisopliae using molecular techniques. Growth performance of isolates on four basal media namely, Potato Dextrose Agar (PDA), Potato Dextrose Agar with 1\% yeast extract (PDAY), Sabaroud Dextrose Agar (SDA) and Sabaroud Dextrose Agar with 1\% yeast extract (SDAY) was assessed. The pathogenicity of each isolate was tested against subterranean termite Coptotermes curvignathus at three concentrations of $1 \times 10^{6}, 1 \times 10^{7}$ and $1 \times 10^{8}$ conidia $\mathrm{mL}^{-1}$. Infections of the isolates were examined using electron microscopy technique. The growth performance of each isolate differed significantly. Among all basal media, only SDAY was able to produce high growth performance and thick conidia mats with all

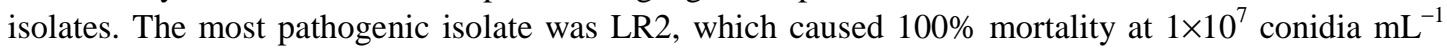
within 3 days post-inoculation. Conclusion/Recommendations: All three isolates were pathogenic against $C$. curvignathus as they were able to germinate and penetrate into the termite cuticle within 15 hours post-inoculation. The three local isolates of $M$. anisopliae var. anisopliae have potential to be developed as biopesticides to control termites, C. curvignathus in oil palm plantations.
\end{abstract}

Key words: Metarhizium anisopliae var. anisopliae, Coptotermes curvignathus, subterranean termite, biopesticides

\section{INTRODUCTION}

Coptotermes curvignathus (Isoptera: Rhinotermitidae) is a common termite pest found attacking the oil palms in Malaysia especially on peat ${ }^{[1]}$. The pest feeds on living tissues of oil palm and thus killing the tree within months. Chemical pesticides such as chlorpyrifos and imidachloprid have been used against $C$. curvignathus, but the effect is only temporary and regular treatments are needed.

The entomopathogenic fungus, $M$. anisopliae, discovered 125 years ago by Mechnichoff has a rather wide host range. It is widely used as a biocontrol agent on various types of pests which include elm bark beetle, mosquito larvae, plant hoppers, coconut leaf beetle, rhinoceros beetle, onion thrips, storage cowpea, white grub, cattle tick and also termite species like Reticulitermes spp., Coptotermes formosanus and Odontotermes formosanus ${ }^{[2-13]}$.

In the world, many mycoinsecticides have been registered and are available for control of both agriculture and household pests, including termites. However, in Malaysia commercial production of $M$. anisopliae is at an infant stage and there is only one product to control rhinoceros beetle, Oryctes rhinoceros (Scarabaeiae) in oil palm ${ }^{[14]}$.

Termite infestations in Malaysia are still being controlled with the use of several chemical insecticides.

Corresponding Author: Choon-Fah J. Bong, Department of Crop Science, Faculty of Agriculture and Food Sciences, University Putra Malaysia Bintulu Campus, Nyabau Road, 97000 Bintulu, Sarawak, Malaysia Tel: 6086-855405 Fax: 6086-855415 
Hence, the identification of novel fungal isolates is being focused to improve termite control ${ }^{[11]}$. Several factors must be addressed to improve the efficacy of M. anisopliae, (i) virulence, (ii) physiological characteristics of the isolate like enzyme production, conidial viability, speed of germination, hyphal growth rate and conidia production and (iii) environmental factors that influence the response of the isolate ${ }^{[4,15-16]}$. In this study, growth characteristics, pathogenicity and infection of three local isolates of $M$. anisopliae were evaluated.

\section{MATERIALS AND METHODS}

Termite source: The researchers of C. curvignathus were baited and collected from an infested oil palm plantation in Sarawak, Malaysia. Collected termites were reared at room temperature $\left(28 \pm 1^{\circ} \mathrm{C}\right)$ and high humidity (RH $80 \%$ ) in dark, plastic containers with peat soil and rubber wood as food. The termites were preconditioned in the laboratory for three days.

Fungal isolates and molecular identification: Three local isolates of M. anisopliae labeled as MG, LR2 and TA were used in the experiment. All three isolates of M. anisopliae were isolated from soil. Both MG and LR2 were isolated from mineral soil collected under fruit trees, while isolate TA was isolated from peat soil collected in an oil palm plantation. The fungi were maintained on Potato Dextrose Agar (PDA) at room temperature $\left(27 \pm 1^{\circ} \mathrm{C}\right)$ in total darkness. One week old actively growing pure cultures were subcultured by placing $3 \mathrm{~mm}$ mycelia plugs into Erlenmeyer flasks containing $50 \mathrm{~mL}$ of Sabaroud Dextrose Broth (Merck) with $1 \%$ of yeast extract (Merck). The broth cultures were incubated as still culture $\left(27 \pm 1^{\circ} \mathrm{C}\right)$ in total darkness for 5 days until a thin layer of mycelia formed on the broth.

To extract genomic DNA, the thin layer of mycelium of each isolate was frozen in liquid nitrogen and ground into a fine powder using a mortar and pestle. DNA was extracted from the mycelia powder using GF-1 Vivantis Bacterial DNA Extraction Kit (Vivantis) according to the manufacturer's protocol with slight modification for the isolation of total DNA. PCR amplification of fungal DNA was performed using $\begin{array}{llll}\text { specific } & \text { primer } & \text { ITSMET }\end{array}$ (5'TCTGAATTTTTTATAAGTAT-3') and ITS4 (5'TCCGTAGGTGAACCTGCGG-3') to generate a PCR product of $440 \mathrm{bp}^{[17]}$. The reaction mixture in $50 \mu \mathrm{L}$ contained $10 \mathrm{X}$ Buffer A, $2 \mathrm{nM}$ dNTP mix, $50 \mathrm{mM} \mathrm{MgCl}_{2}$ (Vivantis), $2 \mathrm{U}$ Taq DNA polymerase (Fermentas), $0.25 \mu \mathrm{L}$ of each primer. The PCR conditions consisted of an initial denaturing step of 3 min at $95^{\circ} \mathrm{C}$ followed by 38 cycles of $94^{\circ} \mathrm{C}$ for $1 \mathrm{~min}$, $46^{\circ} \mathrm{C}$ for $1 \mathrm{~min}$ and $72^{\circ} \mathrm{C}$ for $1 \mathrm{~min}$. The reaction was completed with a final extension at $72^{\circ} \mathrm{C}$ for $3 \mathrm{~min}$ and then cooled and held at $4^{\circ} \mathrm{C}$. PCR samples were separated with $1 \%$ TBE-agarose gel. The products were stained with ethidium bromide and visualized under UV light. Samples of amplified DNA fragment from each isolate were sequenced in both directions. The sequences were compared to those available in the GenBank data base.

Colony morphology and growth performance of the isolates on different culture media: Four types of culture media were tested, namely, Potato Dextrose Agar (PDA) (Merck), Potato Dextrose Agar (PDA) with $1 \%$ yeast extract (Merck), Sabaroud Dextrose Agar (SDA) (Merck) and Sabaroud Dextrose Agar with $1 \%$ yeast extract. A $0.1 \%$ streptomycin sulphate was added to all the media to prevent bacterial contamination. Preliminary studies showed that there were no detrimental effect to the fungi after the antibiotic was added. The media were inoculated using a $3 \mathrm{~mm}$ mycelia disc from a 7 day old culture. Five replicates were prepared for each media and the plates were incubated at room temperature $\left(27 \pm 1^{\circ} \mathrm{C}\right)$ in total darkness in a completely randomized design. Morphological characteristics evaluated were color, texture and colony shape. Diameter of the colony was measured daily with an average of two readings at right angles for a period of 14 days. Data were subjected to analysis of variance using SAS software version 9.1. The experiment was repeated three times.

Pathogenicity test on virulence of the isolates on $\boldsymbol{C}$. curvignathus: The conidia were harvested from two weeks old cultures under sterile conditions by flooding cultures with sterile water containing $0.05 \%$ Tween 80 and lightly scrapping the colonies with a ' $L$ ' rod. The conidia suspension was then vortexed for 20 minutes to detach conidia from the conidiophores and filtered using two layers of cheesecloth. Concentration of conidia suspension was determined with a haemocytometer (Petroff-Hausner) and adjusted to 3 concentrations of $1 \times 10^{6}, 1 \times 10^{7}$ and $1 \times 10^{8}$ conidia $\mathrm{mL}^{-1}$. Ten termites were collected from the pre-conditioned laboratory culture and were placed in a $9 \mathrm{~cm}$ Petri dish to be conditioned overnight in the incubator at $28 \pm 1^{\circ} \mathrm{C}$, $80 \% \mathrm{RH}$. Conidia suspension was topically applied to the thorax of each termite at $10 \mu \mathrm{L}$ per temite.

All treated termites were incubated in the dark at $28 \pm 1^{\circ} \mathrm{C}$ with $80 \% \mathrm{RH}$. Control termites were treated with only $0.05 \%$ Tween 80 solution. Treatments were 
replicated 5 times in a completely randomized design with factorial arrangement. Mortality of termites was checked daily. Dead termites were removed and incubated on moist blotter until cadavers were colonized by $M$. anisopliae to confirm that the termites were killed by the fungus. Termite mortalities were corrected using Abbott's formula before subjecting to data analysis using SAS Version 9.1 ${ }^{[18]}$. Treatment means were separated using Duncan New Multiple Range Test (DNMRT). The experiment was repeated three times.

Infection studies of the local isolates of M. anisopliae on C. curvignathus: Termites were collected and dipped into conidial suspensions with gentle swirling for $5 \mathrm{sec}$ and allowed to dry on two pieces of Whatman No.1 filter paper. Treated termites were separated from each other to prevent grooming activity during the drying process. The termites were then rinsed once in $0.05 \%$ Tween 80 solution to remove any non-attached conidia, before being placed individually into sterile $1.5 \mathrm{~mL}$ microcentrifuge tubes containing a small strip of moist filter paper. Termites treated with only $0.05 \%$ Tween 80 solution served as controls. Ten termites were removed from each tube at 0,15 and $24 \mathrm{~h}$ after inoculation and fixed overnight with $4 \% \quad(\mathrm{v} / \mathrm{v})$ glutaraldehyde in $0.1 \%$ phosphate buffer $(\mathrm{pH} 7.2)$ and washed thrice with sterilized phosphate buffer for 10 min each. They were then postfixed in $1 \%$ osmium tetroxide overnight and dehydrated through a graded ethanol series of $30,40,50,60,75,90$ and $100 \%$. The termite samples were then washed thrice in $100 \%$ acetone subjected to critical point drying and coated with gold-palladium. Conidia attachment, germination and penetration of different isolates were observed using scanning electron microscope (JEOL 5610-XL SEM and Phillips XL30 ESEM).

\section{RESULTS}

Colony morphology and growth performance of the isolates M. anisopliae: All three isolates (MG, LR2, TA) were identified as Metarhizium anisopliae var. anisopliae. The isolate showed different morphological structure on different culture media (Fig. 1 and Table 3). All isolates on different culture media produced round colonies. Isolate MG produced sparse sporulation on SDA compared to other culture media. The greenish layer on the colony surface was the sporulating region (Fig. 1). However, LR2 and TA colonies cultured on PDA exhibited sparse sporulation, while SDAY produced the highest conidia density (Fig. 1). Generally, SDAY and PDA showed significantly higher mean radial growth of 6.17 and $6.19 \mathrm{~cm}$, respectively, compared to SDA and PDAY with growth of 5.65 and $5.89 \mathrm{~cm}$, respectively (Table 1). SDAY produced the thickest conidia (Fig. 1, 2 and 3) and significantly greater colony growth (Table 1). The isolate LR2 had the highest mean growth of $6.54 \mathrm{~cm}$, followed by isolates MG and TA at 6.05 and $5.35 \mathrm{~cm}$, respectively (Table 2). The growth performance on different culture media showed that isolate MG on PDA had the highest growth rate of $0.50 \mathrm{~cm} \mathrm{day}^{-1}$ followed by isolate LR2 on PDAY with $0.49 \mathrm{~cm} \mathrm{day}^{-1}$.
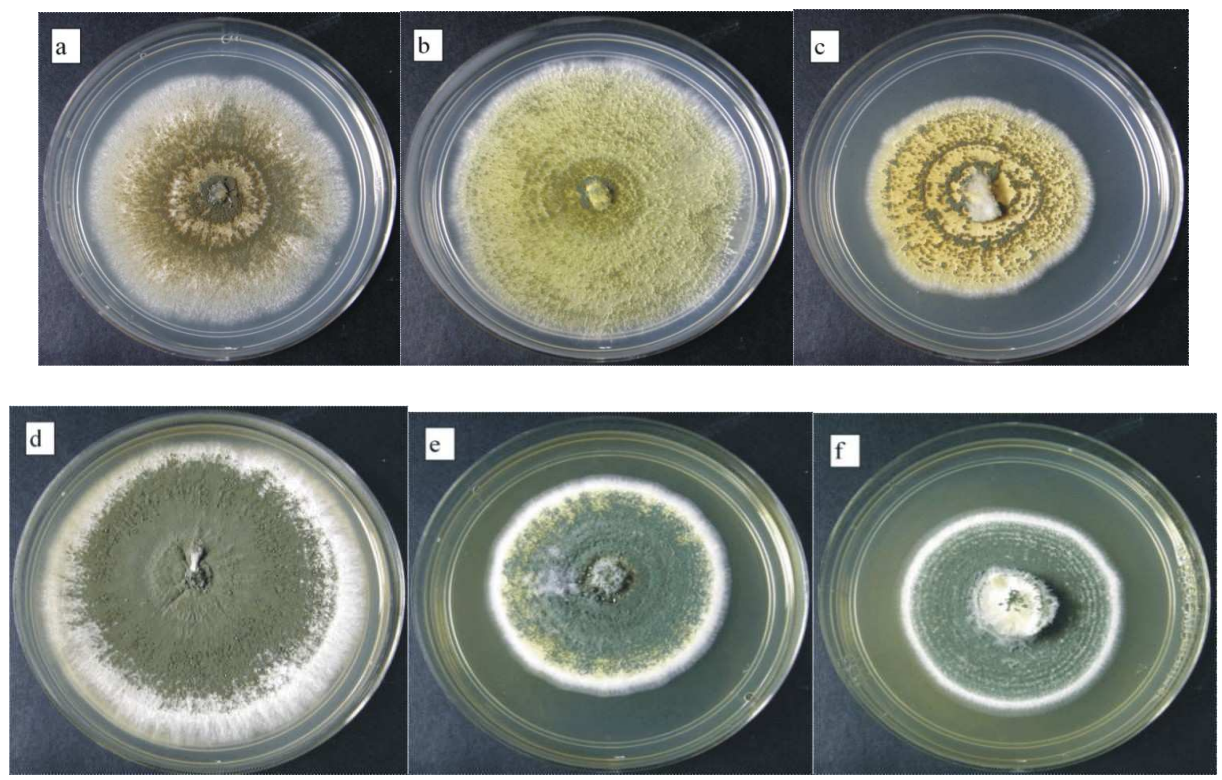

291 

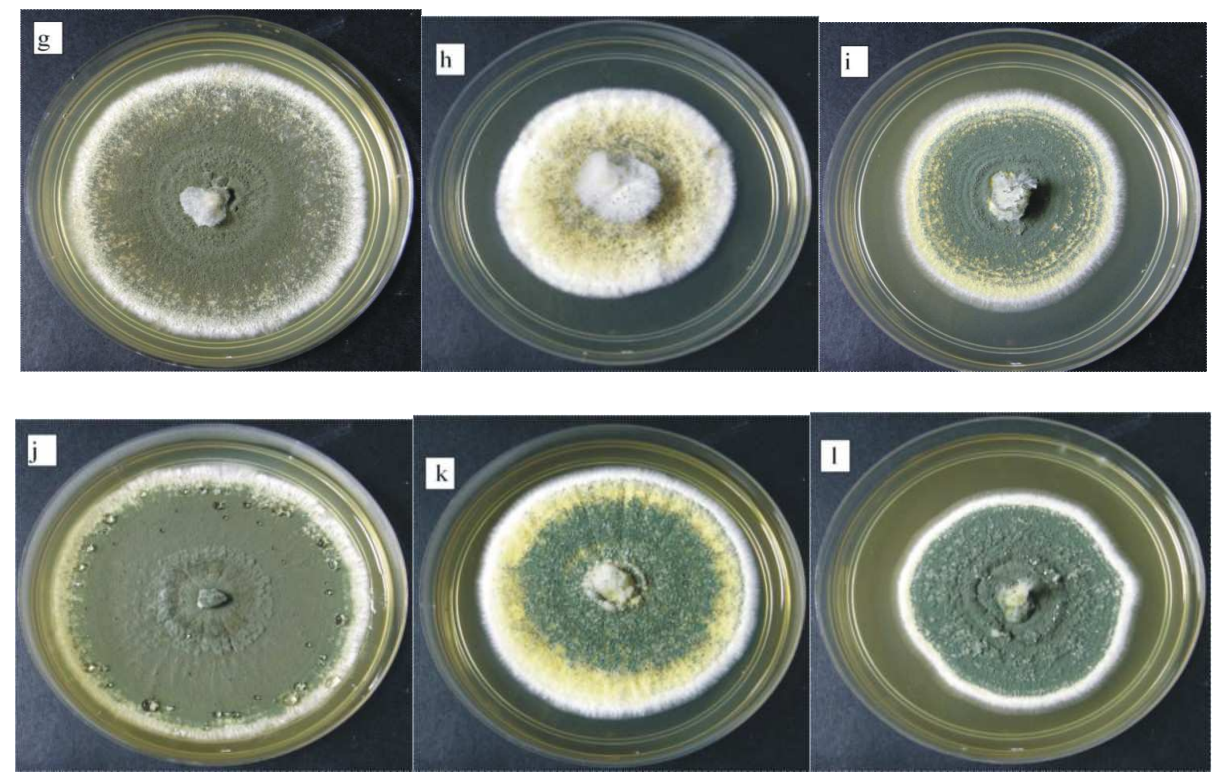

Fig. 1: Cultural morphology of 14 day old M. anisopliae var. anisopliae LR2 isolate (a) LR2 PDA, (b) MG PDA, (c) TA PDA (d) LR2 PDAY (e) MG PDAY (f) TA PDAY (g) LR2 SDA (h) MG SDA (i) TA SDA (j) LR2 SDAY (k) MG SDAY (l) TA SDA

Table 1: Effect of culture media on radial growth of M. anisopliae var. anisopliae after 14 days incubation

\begin{tabular}{ll}
\hline Culture media & $\begin{array}{l}\text { Mean radial } \\
\text { growth }(\mathrm{mm})^{*}\end{array}$ \\
\hline Potato Dextrose Agar (PDA) & $6.19^{\mathrm{a}}$ \\
Potato Dextrose Agar + 1\% Yeast extract (PDAY) & $5.89^{\mathrm{b}}$ \\
Sabaroud Dextrose Agar (SDA) & $5.65^{\mathrm{b}}$ \\
Sabaroud Dextrose Agar + 1 Yeast extract (SDAY) & $6.17^{\mathrm{a}}$ \\
\hline *: Means with same superscript are not significantly different at \\
$\mathrm{p}=0.05$ by Duncan new multiple range test
\end{tabular}

Table 2: Growth of M. anisopliae var. anisopliae isolates 14 days after incubation

\begin{tabular}{ll}
\hline M. anisopliae isolate & Mean radial growth $(\mathrm{mm})^{*}$ \\
\hline TA & $5.35^{\mathrm{a}}$ \\
LR2 & $6.54^{\mathrm{b}}$ \\
MG & $6.05^{\mathrm{c}}$ \\
\hline
\end{tabular}

*: Means with same superscript are not significantly different at $\mathrm{p}=0.05$ by Duncan new multiple range test

The lowest growth rate was recorded in isolates TA on SDA at $0.36 \mathrm{~cm} \mathrm{day}{ }^{-1}$. There were no significant difference in the growth rate of isolate TA on SDA, PDA and PDAY. Isolate LR2 cultured on PDA and PDAY sporulated within 2 days post-inoculation, while it took 5 days post-inoculation for the same isolate to sporulate on SDA. Isolate MG on PDA and PDAY sporulated within 3 days post-inoculation, while on SDA and SDAY sporulation began after 5 days postinoculation. Isolate TA sporulated within 3 days postinoculation in all media (Table 3 ).
Virulence of the isolates on C. curvignathus: The TA, MG and LR2 isolate were pathogenic to C. curvignathus and caused a $100 \%$ mortality at $1 \times 10^{8}$ conidia $\mathrm{mL}^{-1}$ after 3 days post-inoculation for isolate TA and 2 days post-inoculation for isolates MG and LR2 (Table 4). All the three isolates did not cause any mortality in the treated termites during the first day after inoculation although the termites were very weak and hardly moving. The treated termites were hardly able to move from the place where they were inoculated, especially with highest concentration $\left(1 \times 10^{8}\right.$ conidia $\left.\mathrm{mL}^{-1}\right)$. At the lower concentration of $1 \times 10^{7}$ conidia $\mathrm{mL}^{-1}$, isolate TA achieved $100 \%$ mortality at 6 days post-inoculation, while isolate MG and LR2 were able to cause $100 \%$ mortality within 4 and 3 days postinoculation, respectively. At the lowest concentration of $1 \times 10^{6}$ conidia $\mathrm{mL}^{-1}$, all three strains did not cause $100 \%$ mortality in the treated termites, but TA was able to cause $50 \%$ mortality among the treated termites at 4 days post-inoculation. Isolates MG and LR2 took a longer period of 5-6 days post-inoculation to obtain $50 \%$ mortality compared to the other two other isolates when termites were inoculated with low concentration $\left(1 \times 10^{6}\right)$. On the average, the virulence of all three isolates were not significantly different as they caused a $78.67,79.33$ and $78.67 \%$ mortality at 3 day postinoculation for isolate TA, MG and LR2, respectively (Table 5). However, at 3 days post-inoculation, virulence of the isolates differed significantly with different conidia concentrations (Table 6). 
Am. J. Agri. \& Biol. Sci., 4 (4): 289-297, 2009

Table 3: Cultural characteristics of Metarhizium anisopliae var. anisopliae isolates (MG, TA, LR2) on different media

\begin{tabular}{|c|c|c|c|c|c|c|c|}
\hline \multirow[b]{2}{*}{ Isolates/media* } & \multicolumn{2}{|l|}{ Color } & \multirow{2}{*}{$\begin{array}{l}\text { Mycelia } \\
\text { texture }\end{array}$} & \multirow{2}{*}{$\begin{array}{l}\text { Colony } \\
\text { Shape } \\
\text { Mean }\end{array}$} & \multirow{2}{*}{$\begin{array}{l}\text { Growth } \\
\text { rate }\left(\mathrm{mm} \mathrm{day}^{-1}\right) \\
\text { mean }\end{array}$} & \multirow{2}{*}{$\begin{array}{l}\text { Size } \\
(\mathrm{mm})\end{array}$} & \multirow{2}{*}{$\begin{array}{l}\text { No. of } \\
\text { days to } \\
\text { sporulation }\end{array}$} \\
\hline & Top & Bottom & & & & & \\
\hline TA PDA & $\begin{array}{l}\text { Yellow mycelia mat with } \\
\text { circular rings of green conidia }\end{array}$ & $\begin{array}{l}\text { Pale yellowish orange with } \\
\text { radiating orange circular rings }\end{array}$ & Thin and adpressed & Round & $3.7^{\mathrm{a}}$ & $51.6^{\mathrm{a}}$ & 3 \\
\hline TA PDAY & Green conidia covering whole colony & Beige & Thick and adpressed & Round & $3.7^{\mathrm{a}}$ & $51.2^{\mathrm{a}}$ & 3 \\
\hline TA SDA & $\begin{array}{l}\text { Yellow mycelia mat with } \\
\text { circular rings of green conidia }\end{array}$ & $\begin{array}{l}\text { Pale yellowish orange with } \\
\text { orange rings in the centre }\end{array}$ & Thick and adpressed & Round & $3.6^{\mathrm{a}}$ & $50.7^{\mathrm{a}}$ & 3 \\
\hline TA SDAY & Green conidia covering whole colony & $\begin{array}{l}\text { Pale orange with an orange } \\
\text { ring in the centre }\end{array}$ & Thick and adpressed & Round & $4.2^{\mathrm{bc}}$ & $58.3^{\mathrm{bc}}$ & 3 \\
\hline LR2 PDA & $\begin{array}{l}\text { Dark yellow mycelia mat with } \\
\text { dark green conidia on the mycelia mat }\end{array}$ & $\begin{array}{l}\text { White with an orange tint } \\
\text { in the centre }\end{array}$ & Thin and adpressed & Round & $0.46^{\mathrm{b}}$ & $64.4^{\mathrm{d}}$ & 2 \\
\hline LR2 PDAY & Thick green conidia covering whole colony & $\begin{array}{l}\text { Yellow with orange rings } \\
\text { in the centre }\end{array}$ & Thick and adpressed & Round & $4.9^{\mathrm{e}}$ & $69.2^{\mathrm{e}}$ & 2 \\
\hline LR2 SDA & $\begin{array}{l}\text { Green conidia covering whole colony } \\
\text { centre with beige color core }\end{array}$ & Orange circular ring in the & Thick and adpressed & Round & $4.5^{\mathrm{cd}}$ & $62.8^{\mathrm{cd}}$ & 5 \\
\hline LR2 SDAY & $\begin{array}{l}\text { Thick green conidia covering } \\
\text { whole colony }\end{array}$ & $\begin{array}{l}\text { Orange with radiating } \\
\text { grooves in light orange } \\
\text { circular rings }\end{array}$ & Thick and adpressed & Round & $4.6^{\mathrm{b}}$ & $64.0^{\mathrm{d}}$ & 3 \\
\hline MG PDA & $\begin{array}{l}\text { Yellow mycelia mat with } \\
\text { circular rings of green conidia }\end{array}$ & $\begin{array}{l}\text { Pale yellowish orange with } \\
\text { orange rings in the centre }\end{array}$ & Thin and adpressed & Round & $5.0^{\mathrm{e}}$ & $69.4^{\mathrm{e}}$ & 3 \\
\hline MG PDAY & Green conidia covering whole colony & $\begin{array}{l}\text { Orange with circular rings } \\
\text { in the centre }\end{array}$ & Thin and adpressed & Round & $4.0^{\mathrm{b}}$ & $56.4^{\mathrm{b}}$ & 3 \\
\hline MG SDA & $\begin{array}{l}\text { Yellowish mycelia mat with } \\
\text { sparse of green conidia }\end{array}$ & $\begin{array}{l}\text { Yellowish orange, dark } \\
\text { orange in the centre }\end{array}$ & $\begin{array}{l}\text { Thick, cottony and } \\
\text { adpressed }\end{array}$ & Round & $4.0^{\mathrm{b}}$ & $56.0^{\mathrm{b}}$ & 5 \\
\hline MG SDAY & $\begin{array}{l}\text { Yellow mycelia mat with } \\
\text { thick green conidia on the colony }\end{array}$ & $\begin{array}{l}\text { Orange with radiating } \\
\text { grooves on the surface }\end{array}$ & $\begin{array}{l}\text { Thick, cottony } \\
\text { and adpressed }\end{array}$ & Round & $4.3^{\mathrm{bcd}}$ & $59.9^{\mathrm{bcd}}$ & 5 \\
\hline
\end{tabular}

*: PDA = Potato Dextrose Agar, PDAY = Potato Dextrose Agar with 1\% yeast extract, SDA $=$ Sabaroud Dextrose Agar, SDAY $=$ Sabaroud Dextrose Agar with $1 \%$ yeast extract

Table 4: Virulence of isolate TA, MG and LR2 on C. curvignathus

\begin{tabular}{|c|c|c|c|c|c|c|c|}
\hline \multirow[b]{2}{*}{ Treatment (conidia $\mathrm{mL}^{-1}$ ) } & \multicolumn{7}{|c|}{ Mortality $(\%)^{*}$ (day) } \\
\hline & 2 & 3 & 4 & 5 & 6 & 7 & 8 \\
\hline TA $1 \times 10^{6}$ & $38.00^{\mathrm{a}}$ & $48.00^{\mathrm{a}}$ & $52.00^{\mathrm{a}}$ & $52.00^{\mathrm{a}}$ & $52.00^{\mathrm{a}}$ & $62.00^{\mathrm{a}}$ & $64.00^{\mathrm{a}}$ \\
\hline TA $1 \times 10^{7}$ & $86.00^{\mathrm{b}}$ & $88.00^{\mathrm{b}}$ & $92.00^{\mathrm{b}}$ & $94.00^{\mathrm{b}}$ & $100.00^{\mathrm{b}}$ & $100.00^{\mathrm{b}}$ & $100.00^{\mathrm{b}}$ \\
\hline TA $1 \times 10^{8}$ & $98.00^{\mathrm{b}}$ & $100.00^{\mathrm{c}}$ & $100.00^{\mathrm{b}}$ & $100.00^{\mathrm{b}}$ & $100.00^{\mathrm{b}}$ & $100.00^{\mathrm{b}}$ & $100.00^{\mathrm{b}}$ \\
\hline MG $1 \times 10^{6}$ & $36.00^{\mathrm{a}}$ & $40.00^{\mathrm{a}}$ & $42.00^{\mathrm{a}}$ & $48.00^{\mathrm{a}}$ & $50.00^{\mathrm{a}}$ & $56.00^{\mathrm{a}}$ & $64.00^{\mathrm{a}}$ \\
\hline MG $1 \times 10^{7}$ & $92.00^{\mathrm{b}}$ & $98.00^{\mathrm{b}}$ & $100.00^{\mathrm{b}}$ & $100.00^{\mathrm{b}}$ & $100.00^{\mathrm{b}}$ & $100.00^{\mathrm{b}}$ & $100.00^{\mathrm{b}}$ \\
\hline MG $1 \times 10^{8}$ & $100.00^{\mathrm{c}}$ & $100.00^{\mathrm{b}}$ & $100.00^{\mathrm{b}}$ & $100.00^{\mathrm{b}}$ & $100.00^{\mathrm{b}}$ & $100.00^{\mathrm{b}}$ & $100.00^{\mathrm{b}}$ \\
\hline LR2 $1 \times 10^{6}$ & $32.00^{\mathrm{a}}$ & $36.00^{\mathrm{a}}$ & $42.00^{\mathrm{a}}$ & $44.00^{\mathrm{a}}$ & $54.00^{\mathrm{a}}$ & $60.00^{\mathrm{a}}$ & $62.00^{\mathrm{a}}$ \\
\hline LR2 $1 \times 10^{7}$ & $88.00^{\mathrm{b}}$ & $100.00^{\mathrm{b}}$ & $100.00^{\mathrm{b}}$ & $100.00^{\mathrm{b}}$ & $100.00^{\mathrm{b}}$ & $100.00^{\mathrm{b}}$ & $100.00^{\mathrm{b}}$ \\
\hline LR2 $1 \times 10^{8}$ & $100.00^{\mathrm{b}}$ & $100.00^{\mathrm{b}}$ & $100.00^{\mathrm{b}}$ & $100.00^{\mathrm{b}}$ & $100.00^{\mathrm{b}}$ & $100.00^{\mathrm{b}}$ & $100.00^{\mathrm{b}}$ \\
\hline
\end{tabular}

*: Means within columns for each isolate with same superscripts are not significantly different at $\mathrm{p}=0.05$ by Duncan new multiple range test
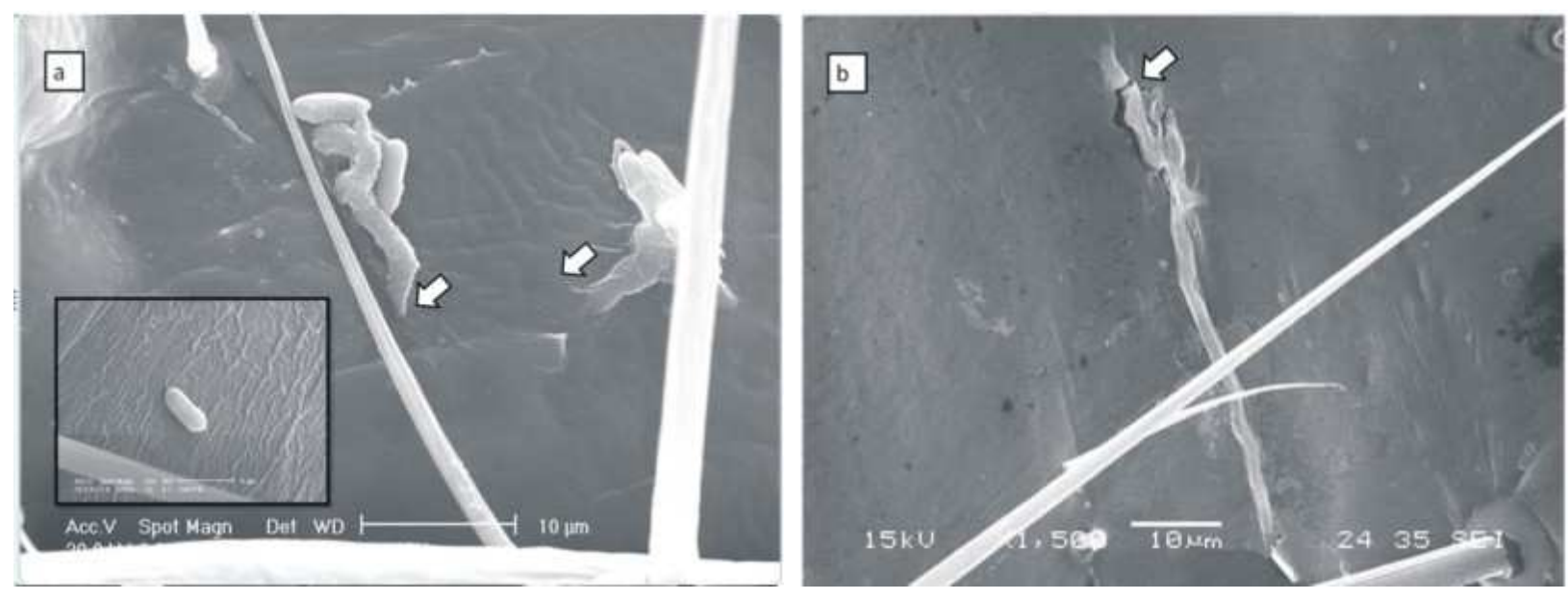

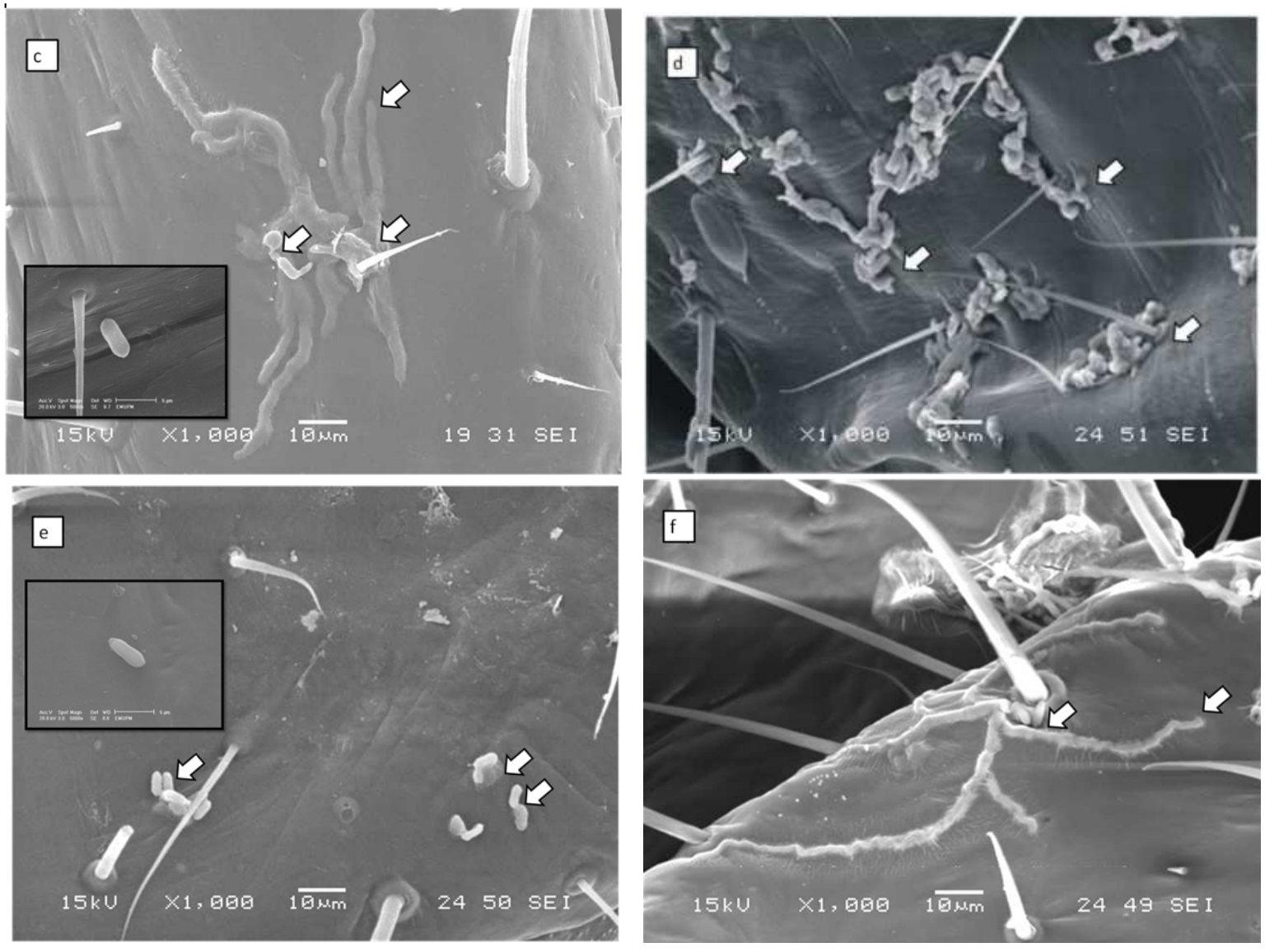

Fig. 2: Post-inoculation penetration and extrusion of mycelia among isolates: (a) Isolate LR2 at $15 \mathrm{~h}$ post inoculation; penetration point (arrow), 2500x; conidia of isolate LR2 at $0 \mathrm{~h}$ post inoculation, 5000x (inset); (b) extrusion of mycelium by isolate LR2 at $24 \mathrm{~h}$ post inoculation; degradation of cuticle (arrow), 1500x; (c) Extrusion of mycelium by isolate MG at $24 \mathrm{~h}$ post inoculation; subcutinous infection (arrow), 1000x; conidia at $0 \mathrm{~h}$ post inoculation, 5000x (inset), (d) penetration of isolate MG at $15 \mathrm{~h}$ post inoculation, 1000x, (e) penetration of isolate TA at $15 \mathrm{~h}$ post inoculation, 1000x; conidia at $0 \mathrm{~h}$ post inoculation, 5000x (inset); (f) extrusion of mycelium by isolate TA at $24 \mathrm{~h}$ post inoculation; subcutinous infection (arrow), 1000x

Table 5: Mortality of C. curvignathus treated with the different isolates at day 3

\begin{tabular}{ll}
\hline Isolate & Mortality $(\%)^{*}$ \\
\hline TA & $78.67^{\mathrm{a}}$ \\
MG & $79.33^{\mathrm{a}}$ \\
LR2 & $78.67^{\mathrm{a}}$ \\
\hline
\end{tabular}

*: Means with same superscript are not significantly different at $\mathrm{p}=0.05$ by Duncan new multiple range test

Table 6: Mortality of C. curvignathus treated with different concentrations of $M$. anisopliae var. anisopliae isolates at day 3

\begin{tabular}{lc}
\hline Conidial concentration (conidia $\mathrm{mL}^{-1}$ ) & Mortality $(\%)^{*}$ \\
\hline $1 \times 10^{6}$ & $41.33^{\mathrm{a}}$ \\
$1 \times 10^{7}$ & $83.33^{\mathrm{b}}$ \\
$1 \times 10^{8}$ & $100.00^{\mathrm{c}}$ \\
\hline
\end{tabular}

*: Means with same superscript are not significantly different at $\mathrm{p}=0.05$ by Duncan new multiple range test
Infection studies of the local isolates on C. curvignathu: The morphology of conidia and infection process of isolates TA, MG and LR2 taken from the cadavers of termites are shown in Fig. 5. The conidia germinated and penetrated into the cuticle of the termite at $15 \mathrm{~h}$ post inoculation (Fig. 5a, d and e). The formation of haloes around the conidia and germination tube on termite cuticle was observed, especially in isolates TA and MG (Fig. 2d and e). A thickening of the germ-tube, characterizing the formation of appresorium, was observed during germination and penetration of conidia in both isolates. In isolate LR2, no haloes were observed when the germ tube and mycelium penetrated into the termite cuticle (Fig. 2a). The occurrence of these haloes appeared to be related to 
the production and excretion of exoenzymes by the isolates during the infective process. Although there was no occurrence of halo during the penetration of germ tube by isolate LR2, degradation of termite cuticle was observed at $24 \mathrm{~h}$ post-inoculation (Fig. 2b). At $24 \mathrm{~h}$ post-inoculation, the spreading of mycelium with degradation of cuticle caused the termite to be weakened. Mycelia of MG and TA isolates proliferated beneath the cuticle of the termite's abdomen (Fig. 2c and f) at $24 \mathrm{~h}$ post-inoculation. The mycelia of LR2 isolate however only spread on the cuticle surface.

\section{DISCUSSION}

Radial growth of fungi isolates differed significantly among isolates and type of basal medium used for culturing. Metarhizium anisopliae var. anisopliae isolate MG showed the highest radial growth on PDA but with sparse sporulation, compared to less radial growth but with thick conidia mats on SDAY. SDAY did not differ significantly with PDAY and SDA in terms of mean radial growth of the colony. Addition of yeast extract increased the production of conidia slightly. Isolate LR2 provided the second highest radial growth on PDAY, although it produced relatively high growth rates on all the other three media when compared to other isolates. The sporulation of isolate LR2 was sparse when yeast extract was not added to the basal media. Isolate TA had the slowest growth performance among all the three isolates, but when cultured on SDAY, mean radial growth increased significantly. Visual observation showed differences in conidia density on the colonies cultured in different media. Both LR2 and TA isolate has sparse sporulation on PDA compared to SDA and they differed significantly, while isolate MG cultured on both SDA and PDA had sparse sporulation. Some strains of $M$. anisopliae and Beauveria bassiana have been reported to produce high to maximum conidial yield on SDA media which had a $\mathrm{C} / \mathrm{N}$ ratio equivalent of $35: 1^{[19,20]}$. Conversely, it had also been reported that several isolates of $B$. bassiana and M. anisopliae were able to produce maximum yield of conidia on PDA a low $\mathrm{C} / \mathrm{N}$ ratio equivalent medium of $10: 1^{[19,20,22]}$. Some isolates of entomopathogens like $B$. Bassiana, M. anisopliae and Paecilomyces fumosoroseus cultured in liquid medium with low $\mathrm{C} / \mathrm{N}$ ratio of 10:1 also resulted in maximum sporulation ${ }^{[23]}$.

In this study, isolate MG developed thick, fluffy colonies when cultured on SDA and SDAY medium, but sparse sporulation on the former and thick sporulation on the latter. Apparently the addition of yeast extract increased the amount of nitrogen in the media which caused increased sporulation. Nitrates and nitrites produce intermediate growth, but calcium nitrate result in greater sporulation ${ }^{[24]}$. The supply of carbon source is (i) for the synthesis of critical constituents such as carbohydrates, proteins, lipids and nucleic acids, (ii) as a source of energy for proper functioning of the essential life processes of fungi, (iii) for vegetative growth and (iv) for promoting growth of fungi ${ }^{[24]}$. On the average, growth and sporulation was not only closely related to isolates but also culture media as there were significant differences among all three isolates and in different culture media used. All the three isolates were considered quick sporulation types as they were able to sporulate within 2-3 days post-inoculation in most media though they were able to sporulate better in PDA and PDAY. However, sporulation may be reduced after 2 week postinoculation as PDA produced sparse sporulation. Culture media that have a high growth rate may not produce high sporulation. The results revealed a strong correlation between growth rate and virulence.

Isolate LR2 with a high growth rate in all culture media was the most pathogenic, causing $100 \%$ mortality at $1 \times 10^{7}$ conidia $\mathrm{mL}^{-1}$ within 3 days postinoculation. Meanwhile, isolate TA which had the lowest growth rate among all media caused $100 \%$ mortality at $1 \times 10^{7}$ conidia $\mathrm{mL}^{-1}$ within 6 days postinoculation. At the lowest concentration of conidia suspension, $1 \times 10^{6}$ conidia $\mathrm{mL}^{-1}$, all isolates did not to produce $100 \%$ mortality even after one week postinoculation. This may be due to the defensive behavior of termites, where conidia may be groomed off by other members. At $1 \times 10^{6}$ conidia $\mathrm{mL}^{-1}$, approximately only 10 conidia were estimated to attach on the termite's body. Thus, colonization of the termite may take some time and this gives infected termites time to groom each other or exhibit necrophoric behavior. The conidia may have been groomed off before germination could take place. Germination rate is a trait that is frequently related with the virulence ${ }^{[25]}$. High and quick sporulation of an entomopathogen gives a better advantage to control a host insect ${ }^{[26]}$. These characteristics are favored especially in the control of termites as the conidia should be able to infect the termite before being cleaned during grooming.

Defensive grooming behavior enables termites to clean themselves of any foreign contaminants such as fungal conidia. Coptotermes formosanus were able to groom conidia of $M$. anisopliae within hours after inoculation $^{[27]}$. All the three isolates in this study were pathogenic against $C$. curvignathus as they are able to germinate and penetrate into the termite cuticle within $15 \mathrm{~h}$ post inoculation. High growth performance of the 
M. anisopliae var. anisopliae isolates also showed that these isolates were compatible to germinate and penetrate into the termite cuticle and break the defensive necrophoric and grooming behavior. These isolates also produce exoenzymes that aid the penetration process. Conidia of $M$. anisopliae produce three types of enzymes namely Pr1, esterase and NAG'ase, which are involved in the cuticle penetration process, pathogenesis and activity against chitin component of the cuticle ${ }^{[28,29]}$. Cuticle-degrading Pr1 enzyme is determined as a pathogenicity determinant in most entomopathogenous hyphomycetes. This enzyme has an established role in virulence towards insect hosts ${ }^{[30]}$. There are many stages in the process of infection during which the ability of an isolate to cause disease may be influenced. A $M$. anisopliae isolate that rank highly in all the three characteristics of virulence, high sporulation and total sporulation, produced better epizootics compared to an inferior isolate ${ }^{[11]}$.

\section{CONCLUSION}

The three local isolates MG, LR2 and TA of M. anisopliae var. anisopliae have potential to be developed as biopesticides to control termites, C. curvignathus in oil palm plantations. All three isolates possessed the characteristics of high virulence, high growth performance and quick and high sporulation. At low concentration of $1 \times 10^{7}$ conidia $\mathrm{mL}^{-1}$, the isolates were able to cause $100 \%$ mortality within 2-6 days post-inoculation. However, more work is needed to test methods of application before these strains can be commercialized.

\section{ACKNOWLEDGEMENT}

The researchers would like to thank S.C. Wong and P.H. Yiu for their help and use of the molecular biology laboratory and Woodman oil palm plantation for the field work. This study was supported by e-Science Fund No. 05-01-04-SF0516 of the Ministry of Science, Technology and Innovations, Malaysia.

\section{REFERENCES}

1. Wood, B.J., 1968. Pest of Oil Palms in Malaysia and their Control. The Incorporated Society of Planters, pp: 204.

2. Doberski, J.W., 1981. Comparative laboratory studies on three fungal pathogens of the elm bark beetle Scolytus scolytus: Pathogenicity of Beauveria bassiana, $M$. anisopliae and Paecilomyces farinosus to larvae and adults of S. scolytus. J. Invertebr. Pathol., 37: 188-194. DOI: 1016/0022-2011(81)90075-6
3. Daoust, R.A., M.G. Ward and D.W. Roberts, 1982. Effect of formulation on the virulence of M. anisopliae conidia against mosquito larvae. J. Invertebr. Pathol., 40: 228-236. DOI: 10.1016/0022-2011(83)90214-8

4. Samuels, K.D., J.B. Heale and M. Llewellyn, 1989. Characteristics relation to the pathogenicity of M. anisopliae toward Nilaparvata lugens. J. Invertebr. Pathol., 53: 25-31. DOI: 10.1016/00222011(89)90070-0

5. Liu, S.D., S.C. Lin and J.F. Shiau. 1989. Microbial control of coconut leaf beetle (Brontispa longissima) with green muscardine fungus, $M$. anisopliae. J. Invertebr. Pathol., 53: 307-314. DOI: 10.1016/0022-2011(89)90094-3

6. Maniania, N.K., S. Sithanantham, S. Ekesi, K. Ampong-Nyarko, J. Baumgärtner et al., 2003. A field trial of the entomogenous fungus $M$. anisopliae for control of onion thrips, Thrips tabaci. Crop Protect., 22: 553-559. DOI: 10.1016/S02612194(02)0221-1

7. Cherry, A.J., P. Abalo and K. Hell, 2005. A laboratory assessment of the potential different isolates of the entomopathogenic fungi Beauveria bassiana (Balsamo) Vuillemin and M. anisopliae (Metchnikoff) to control Callosobruchus maculates (F.) (Coleoptera: Bruchidae) in stored cowpea. J. Stored Prod. Res., 41: 295-309. DOI: 10.1016/j.jspr.2004.04.002

8. Samson, P.R., R.J. Milner, E.D. Sander and G.K. Bullard, 2005. Effect of fungicides and insecticides applied during planting of sugarcane on viability of $M$. anisopliae and its efficacy against white grubs. Bio Control, 50: 151-163. DOI: 10.1007/s10526-004-0419-y

9. Bahiense, T.C., E.K.K. Fernandes and V.R.E.P. Bittencourt, 2006. Compatibility of the fungus $M$. anisopliae and deltamethrin to control a resistant isolate of Boophilus microplus tick. Vet. Parasitol., 141: 319-324. DOI: 10.1016/j.vetpar.2006.05.011

10. Kramm, K.R., D.F. West and P.G. Rockenbach, 1982. Termite pathogen: Transfer of the entomopathogen $M$. anisopliae between Reticulitermes sp. termites. J. Invertebr. Pathol., 40: 1-6. DOI: 10.1016/0022-2011(82)90029-5

11. Sun, J., J.R. Fuxa and G. Henderson, 2003. Effects of virulence, sporulation and temperature on M. anisopliae and Beauveria bassiana laboratory transmission in Coptotermes formosanus. J. Invertebr. Pathol., 84: 38-46. DOI: 10.1016/s00222011(03)00122-8 
12. Wang, C. and J.E. Powell, 2004. Cellulose bait improves the effectiveness of $M$. anisopliae as a microbial control of termites (Isoptera: Rhinotermitidae). Biol. Control, 30: 523-529. DOI: 10.1016/j.biocontrol.2004.02.00

13. Dong, C., J. Zhang, H. Huang, W. Chen and Y. Hu, 2009. Pathogenicity of new China variety of Metarhizium anisopliae ( $M$. anisopliae var. dcjhyium) to subterranean termite Odontotermes formosanus. Microbiol. Res., 164: 27-35. DOI: 10.1016/j.micres.2006.11.009

14. St. Leger, R.J., M. Goettel, D.W. Roberts and R.C. Staples, 1991. Prepenetration events during infection of host cuticle by $M$. anisopliae. J. Invertebr. Pathol., 58: 168-179. DOI: 10.1016/0022-2011(91)90061-T

15. Milner, R.J., J.A. Staples and G.G. Lutton, 1997. The effect of humidity of germination and infection of termites by the hyphomycete, M. anisopliae. J. Invertebr Pathol., 69: 64-69. DOI: 10.1006/jipa.1996.4636

16. Arthur, S. and M. Thomas, 2001. Effects of temperature and relative humidity on sporulation of M. anisopliae var. acridum in mycosed cadavers of Schistocerca gregaria. J. Invertebr. Pathol., 78: 59-65. DOI: 10.1006/jipa.2001.5050

17. Destéfano, R.H.R., S.A.L. Destéfano and C.L. Messias, 2004. Detection of M. anisopliae var. anisopliae within infected sugarcane borer Diatraea saccharalis (Lepidoptera: Pyralidae) using specific primers. Genet. Mol. Biol., 27: 245-252. DOI: 47572004000200020

18. Abbott, W.S., 1925. A method of computing the effectiveness of an insecticide. J. Econ. Entomol., 18: 265-267.

19. Safavi, S.A., F.A. Shah, A.K. Pakdel, G.R. Rasoulian, A.R. Bandani and T.M., Butt, 2007. Effect of nutrition on growth and virulence of the entomopathogenic fungus Beauveria bassiana. FEMS Microbiol. Lett., 270: 116-123. DOI: 10.1111/j.1574-6968.2007.00666.x

20. Shah, F.A., C.S. Wang and T.M. Butt, 2005. Nutrition influences growth and virulence of the insect-pathogenic fungus $M$. anisopliae. FEMS Microbiol. Lett., 251: 259-266. DOI: 10.1016/j.femsle.2005.08.010

21. Kamp, A.M. and M.J. Bidochka, 2002. Conidium production by insect pathogenic fungi on commercially viable agars. Lett. Applied Microbiol., 35: 74-77. DOI: 10.1046/j.1472765X.2002.01128.x
22. Wyss, G.S., R. Charudattan and J.T. DeValerio, 2001. Evaluation of agar and grain mediafor mass production of conidia of Dactylaria higginsii. Plant Dis., $\quad$ 85: 1165-1170. DOI: 10.1094/PDIS.2001.85.11.1165

23 Vega, F.E., M.A. Jackson, G. Mercadier and T.J. Poprawski, 2003. The impact of nutrition on conidia yields for various fungal entomopathogens in liquid culture. World J. Microbiol. Biotechnol., 19: 363-368. DOI: 10.1023/A:1023924304456

24. Garraway, M.O. and R.C. Evans, 1984. Fungal Nutrition and Physiology. 1st Edn., John Wiley and Sons, Inc., USA., ISBN: 13: 978-0894646317, pp: 412.

25. Hall, R.A., 1984. Epizootic potential for aphids of different isolates of the fungus Verticillum lecanii. Entomophaga, 29: 311-321. DOI: 10.1007/BF02372119

26. Hall, R.A., 1984. Epizootic potential for aphids of different isolates of the fungus Verticillum lecanii. Entomophaga, 29: 311-321. DOI: 10.1016/S00222011(02)00152-0

27. Yanagawa, A. and S. Shimizu. 2007. Resistance of the termite Coptotermes formosanus Shiraki to Metarhizium anisopliae due to grooming. Biol. Control, 53: 75-85. DOI: 10.1007/s10526-0069020-X

28. St. Leger, R.J., A.K. Charnleay and R.M. Cooper, 1986. Cuticle-degrading enzymes of entomopathogenic fungi: Mechanisms of interaction between pathogen enzymes and insect cuticle. J. Invertebr. Pathol., 47: 295-302. DOI: 10.1016/0022-2011(86)90099-6

29. St. Leger, R.J., K. Durrandps, A.K. Charnleay and R.M. Cooper, 1988. Role of extracellular chymoelastase in the virulence of $M$. anisopliae for Manduca sexta. J. Invertebr. Pathol., 52: 285-293. DOI: 10.1016/0022-2011(88)90137-1 